\title{
Service Learning for Empowering Tribal Peoples with Living Labs for Medical Ed- ucation Reform in Taiwan
}

\author{
Duujian Tsai ${ }^{1}$ Tsung Ping Yu ${ }^{2}$ Yu Chia Chen ${ }^{1}$ Shyh-Dye Lee ${ }^{1}$ \\ ${ }^{1}$ Taipei Medical University \\ ${ }^{2}$ Taiwan SECOM \\ ${ }^{3}$ Social Empowerment Alliance \\ ${ }^{4}$ National Taipei University of Nursing and Health Science
}

\begin{abstract}
This project is establishing a platform for Living Lab experiments using smart technology in tribal areas of Taiwan, with the goal of empowering high mountain indigenous peoples. We are forging a learning environment through partnerships between universities, tribal peoples and technology companies that incorporate participatory practices into technology design. The project also employs oral history taking as part of a service learning curriculum to make minorities an integral part of designing new technology applications and possible business models. We aim to foster a new sense of professionalism that incorporates civic engagement and considers technologies as tools for conscious social change.
\end{abstract}

Keywords: Indigenous people, Smart technology, Oral history, Participatory practice, Professionalism

\section{Introduction}

Living Labs are an experimentation environment aimed at shaping technology for real-life contexts; researchers have proposed this approach as especially well suited to ICT innovation for rural areas or for the elderly [1-3]. However, in most Living Labs, the traditional approach to research remains dominant in different stages of product development or service innovation, rather than actually including users in a co-creator approach [4]. Still, there have been promising efforts to bring Living Lab methodologies closer to the ideal of user innovation [5,6]. Some medical schools use service-learning approach, establishing community partnerships and promoting Information and Community Technology (ICT) as a way of cultivating medical students' ability and reducing health gaps. We are trying to further develop existing approaches to service learning by incorporating the idea of user innovation embedded in the concept of Living Labs as a way of empowering people in need.

The ideal of empowerment is reflected in the trend to incorporate service learning aimed at humanistic goals into curriculum reform, especially in medical universities in Taiwan $[7,8]$. Community partnerships that involve a patientcentered approach in clinical settings are very similar to the concept of participatory design seen in Living Labs [9]. Such partnerships have become a major strategy for overcoming health gaps related to cultural barriers [10] and to achieve better outcomes in difficult health situations, such as in the process of cancer treatment [11]. Combining narrative medicine with smart technology applications has poten- 
tial for resolving obstacles to community building and health promotion [12]. It is therefore important to cultivate medical students' competence as facilitators capable of bringing users into the process of technology innovation.

This action-based research is working to establish a platform for smart technology development in tribal areas using the Living Labs approach, with the goal of empowering high mountain indigenous peoples and ameliorating their marginal position in Taiwan. We address the following research questions: Using a definition of Living Labs proposed by Ballon et al., [1], how can we design a service learning curriculum that lets students contribute to "an experimentation environment in which technology is given shape in real-life contexts and in which (end) users are considered 'coproducers'"? In what ways can an interdisciplinary approach help to map a Living Lab onto an experimental tribe, in developing "a systemic innovation approach in which all stakeholders in a product, service or application participate directly in the development process" [13]?

\section{Medical Humanities and Participa- tory Technology Design}

The concept of Living Labs originated from MIT professor William Mitchell, a prominent leader in MediaLab and the School of Architecture and City Planning who proposed it as a participatory methodology for researching users' real living environments, with the goal of innovation of services, products or applications. This approach is well suited to ICT innovation. It has not only served as a tool for validating technology innovations, such as smart homes tailored to meet the needs of specific individuals or groups of people; it also has been adapted for embedding smart technology into creative urban planning[1].
In 2008, Taiwan adopted a "Smart Living Industrial Technology Promotion Strategy" as a major aspect of national policy aimed at realizing an "Intelligent Taiwan," e.g., an infrastructure and way of life that makes maximum use of the potential of smart technologies. With the medical profession currently facing unprecedented challenges, medical humanities enhances professionals' capabilities for facing new technological developments and social environmental challenges, as well as cultivating a high degree of self-reflection in the medical profession $[14,15]$. With the popularity of community-oriented service-learning courses, there is hope for fostering a new sense of professionalism that incorporates civic engagement, for example, considering the application of smart technologies in terms of their social consequences, and regarding such technologies as tools for conscious social change. Mulder and Stappers [4] have described community-driven innovation employing "a user as cocreator approach incorporating the user's context." According to Eriksson, Niitamo and Kulkki [5], the Living Lab concept of a collaborative setup for shaping technology and applications can generate new understandings of future opportunities. Our project uses the concept of Living Labs to create a systematic and participatory approach to providing health care and strengthening community in tribal areas.

\section{Methodology}

We are establishing an experimental field by providing smart technology to assist the indigenous elderly in Nan-ao Township, in cooperation with Saint Mary's Hospital Luodong, the Health Bureau of Yilan County, Secom, one of the leading tele-care companies, the health care device industry, tribal leaders and 
their community health promotion networks (Figure 1).

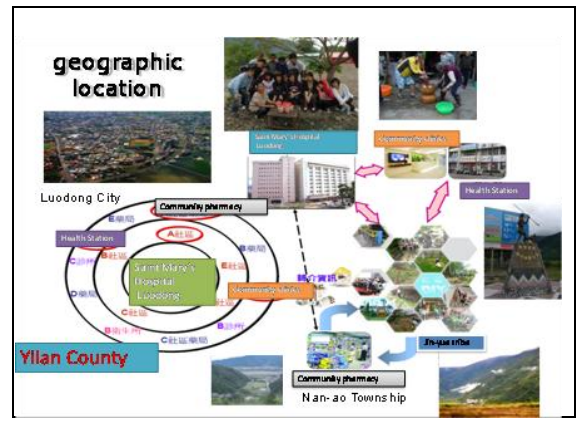

Fig. 1: The experimental field.

This project is mainly focused on the Jin-yue tribe in Nan-ao Township. This is a small tribe of around six hundred people living in a stunningly beautiful, yet remote mountain landscape. Through the combined efforts of the Jin-yue Tribal Community Development Association and their university partners, we have been recovering and preserving traditional Jin-yue cultural skills.

This project integrates service learning activities of students with the provision of medical devices and services for elderly in need through an interdisciplinary student workshop designed to further empower the medical device users in this tribe. Six third-year medical students (who just finished their premedical education) and six masters students at an IT institute were put into six pairs to work as interdisciplinary teams. All students had a preliminary concept of living labs. First, oral history taking on August 20 enabled them to learn from the device users about their life experiences in general. Next, they collected the users' health-related narratives on Aug 21. Students then continued to work in pairs to design prototype ICT projects for the tribe. They reported the results of this collaborative design effort on the university campus on August 30. Students made final presenta- tions of their designs to the three research team members, two outside scholars, seven community leaders and some other community participants on September 3 (Figure 2).

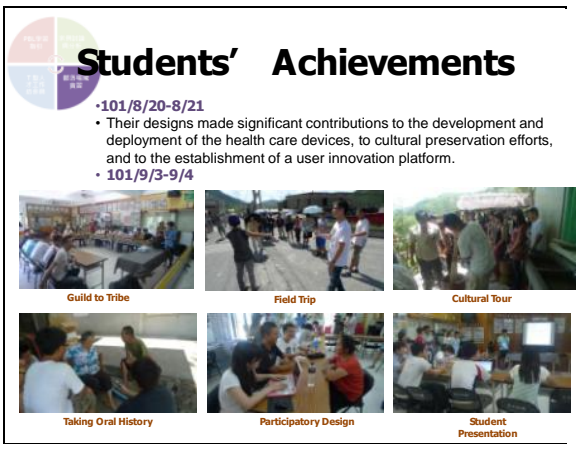

Fig. 2: Student workshop.

\section{Findings}

Of six student presentations, three were health oriented and the other three were related to cultural affairs. The first group designed a health promotion platform that would connect the individual with the community health center through interfamily networking. The second group designed a smart medication box that not only fit easily into different daily life activities, but hat also collected and pooled information that could be used to track results for collective health maintenance efforts. The third group incorporated the device user's wish to preserve traditional weaving culture into a proposal for building a tribal smart classroom. The fourth group devised a smart poke walker with features that include a built-in urgent communication device, a falling monitor and the ability to share information about collective walking activities with members of the user's support network. The fifth group created an interactive composition platform for preserving songs and dances in tribal areas. The final group constructed a smart plotting IT platform 
to incorporate raw material from oral histories, photos, home videos, audios and so on into various products, including films for uploading on You Tube. With the participation of the medical device users in the community, the students clearly enriched the user innovation platform and its usefulness for health promotion and cultural preservation. Their contributions were not limited to either the cultural domain or health issues, but created bridges between both arenas. Afterwards, students' feedback showed they were fully aware of the cultural barriers and information disparity in this tribal area, and were attuned to the consequences in terms of social justice.

This pragmatic participatory project made use of oral life histories, health related narratives, and allowed user's narratives to contribute to design, and also benefitted the students. The students' activities served as critical bridges sensitizing device users to the way they perceive technology. As a result, the device users became more capable and willing to take an active part in community building and promoting health. Furthermore, by observing behavioral changes among the tribe members who participated in the project, the leaders of the tribal association became convinced that they are capable of managing a community health building project for the elderly. They initiated a voluntary biweekly meeting for health promotion shortly after our workshop.

\section{Discussion and Conclusions}

The concept of user innovation provides a feasible approach to building bridges between tribe members and students aimed at promoting community health. Students' teamwork and oral history taking successfully cultivated sufficient familiarity and confidence among the Jin-Yue participants and the students themselves dealing with health-related information technology and established a good working partnership between the student groups and community residents. After this workshop, the Tribal Community Building Association and the research team have been able to work together at transforming an indigenous tribe to become "an experimentation environment where technology is given shape in real-life contexts" [1]. Moreover, the service learning design of this project succeeded at getting students to act as facilitators empowering tribal residents as innovative technology users. With an IT platform to manage and share various kinds of information for daily life that incorporates a user-oriented approach to knowledge management and a feedback mechanism [16], we are developing a cocreation approach to innovation that enables all stakeholders to participate directly in the development of technology products, services or applications. The interdisciplinary teams of student designers learned to consider the social consequences of smart technologies and became aware that empowering local residents as co-designers can contribute to humanistic social change.

In the workshop, students working with device users design ICT products through a mutually supportive participatory approach. At the same time, major stakeholders in this indigenous tribe are developing an innovative platform that can serve as a foundation for community health building. Empowerment and userdriven innovation are key concepts for developing new service models and possible business models. The Living Lab concept, with its appreciation of user innovation, can also serve as a tool for mediating between interest groups and stakeholders in the quest for broader social justice in Taiwan. 


\section{References}

[1] P. Ballon, J. Pierson, and S. Delaere. "Open Innovation Platforms for Broadband Services: Benchmarking European Practices," Proceedings of 16th European Regional Conference, Porto, Portugal, September 4-6, 2005.

[2] H. Schaffers and S. Kulkki, "Living labs-An open innovation concept fostering rural development," Tech Monitor, Sep-Oct., pp. 30-8, 2007.

[3] H. Drachsler, W. Kicken, M. van der Klink, S. Stoyanov, H. Boshuizen and P. Barach, "The Handover Toolbox: a knowledge exchange and training pl atform for improving patient care," BMJ Qual Saf, Dec;21 Suppl 1, pp.114-20, 2012.

[4] Mulder, I. \& Stappers, PJ. (2009) Cocreating in Practice: Results and Challenges. Proceedings of the 15th. International Conference of Concurrent Enterprising.

[5] Eriksson, M., V. P. Niitamo, and S. Kulkki. (2005). State-of-the-art in utilizing Living Labs approach to usercentric ICT innovation - a European approach.

[6] Choenni, R. Waart, P. van. van, \& Haan, G. de. (2011) Proc. ECIME 2011, 5th European Conf. On Information Management and Evaluation, Como, Italy, Sept. 8-9, Academic Publishing Limited, UK, pp. 101108.

[7] Tsai, Duujian 2008, "Communityoriented Curriculum Design for Medical Humanities", Kaohsiung J Med Sci, Volume 24(7). July, pp. 373-379.

[8] Chou, Jen-Yu Chiung-Hsuan Chiu, Enoch Lai, Duujian Tsai, and ChiiRuey Tzeng Medical education in Taiwan Medical Teacher201234:3, 187-191.

[9] Chomitz VR, McGowan RJ, Wendel JM, Williams SA, Cabral HJ, King SE, Olcott DB, Cappello M, Breen
S,Hacker KA. 2010. Healthy Living Cambridge Kids: a community-based participatory effort topromote healthy weight and fitness.Obesity (Silver Spring). 2010 Feb;18 Suppl 1:S45-53.

[10] Javier JR, Chamberlain LJ, Rivera KK, Gonzalez SE, Mendoza FS, Huffman LC.2010. Lessons learned from a community-academic partnership addressingadolescent pregnancy prevention in Filipino American families. Prog Community Health Partnersh. 2010 Win-ter;4(4):305-13.

[11] Attree P, Morris S, Payne S, Vaughan S, Hinder S. 2011. Exploring the influence of service user involvement on health and social careservices for cancer. Health Ex-pect. 2011 Mar;14(1):48-58.

[12] Born K, Orkin A, VanderBurgh D, Beardy J. 2012. Teaching wilderness first aid in a remote First Nations community: the story of the Sachigo Lake WildernessEmergency Response Education Initiative. Int J Circumpolar Health. 2012;71.

[13] Feurstein, K., Hesmer, A., Hribernik, K. A., Thoben, K.-D., \& Schumacher, J. (2008). Living Labs: A New Development Strategy. In J. Schumacher \& V-P. Niitamo: Euro-pean Living Labs: A new approach for human centric regional innova-tion. Berlin: Wissenschaftlicher Verlag Berlin. ISBN 978-3-86573-343-6.

[14] Cassel EJ. The place of the humanities in medicine. New York: The Hastings Center, 1984.

[15] Carson RA, Burns CR, Cole TR (eds). Practicing the Medical $\mathrm{Hu}$ manities: Engaging Physicians and Patients. Hagerstown, MD: University Publishing Group, 2003.

[16] Hsieh CT, Lin B.2011. Information technology for competitive advantage: the case of learning and innovation inbehavioural healthcare 
service. Int $\mathbf{J}$ Electron Healthc.

2011;6(2-4):213-28. 